\title{
Impact of Focussed Care in Heart Failure Patients on Hospital Readmission and Mortality
}

\author{
Jude James ${ }^{1, *}$, Stephy PS ${ }^{1}$, Jeeva Joseph ${ }^{1}$, Suja Abraham¹, Jabir Abdullakutty ${ }^{2}$ \\ 'Nirmala College of Pharmacy Muvattupuzha, Kerala, INDIA. \\ ${ }^{2}$ Cardiologist Lisie Hospital, Cochin, Kerala, INDIA.
}

\begin{abstract}
Objectives: To compare patient health outcomes like mortality and rehospitalisation among heart failure patients receiving focussed care under HF clinics and those receiving usual care under regular cardiac outpatient department. Methods: A total of 200 heart failure patients who consulted in Heart Failure clinic and general cardiology outpatient department during the year of 2017 who satisfied the inclusion and exclusion criteria were selected for the study. The study was carried out in a tertiary care Interventional Cardiology and Cardiac Surgery hospital with a dedicated well established heart failure clinic in Kerala, for a period of 1 year. Patients were followed retrospectively for a period of one year and relevant patient data were obtained from the electronic medical record. The data collected were then evaluated for health outcomes like rehospitalisation and mortality among the two groups. Results: Among the total number of rehospitalisation's reported, only $32.8 \%$ of them were from Heart Failure clinic while $67.2 \%$ of reported rehospitalisation's were from general cardiology outpatient department. Chi square test was applied
\end{abstract}

and statistically significant difference was obtained when mortality rate was compared between the two study groups. $80 \%$ of reported cases of death was among patients who consulted in general cardiology outpatient department while only $20 \%$ was from Heart Failure clinic. Conclusion: Management of heart failure patients in heart failure clinic was associated with significant reduction in one year mortality and rehospitalisation.

Key words: Heart Failure, Heart failure clinics, Rehospitalisation, Mortality, Cardiology, Cardiac care.

Correspondence

Mr. Jude James, Pharm D.,

Pharm D Nirmala College of Pharmacy, Muvattupuzha-686661, Kerala, INDIA.

Phone: +919400397093

Email: judejames666@gmail.com

DOI: 10.5530/jyp.2020.12.72

\section{INTRODUCTION}

Heart Failure (HF) is a clinical syndrome characterized by typical symptoms (e.g. Breathlessness, ankle swelling and fatigue) that may be accompanied by signs (e.g. elevated jugular venous pressure, pulmonary crackles and peripheral edema) caused by a structural and/or functional cardiac abnormality, resulting in a reduced cardiac output and or elevated intracardiac pressures at rest or during stress. ${ }^{1}$ Approximately $1-2 \%$ of the adult population in developed countries has Heart Failure (HF), with the prevalence rising to $\geq 10 \%$ among persons 70 years of age or older. ${ }^{2,3}$ Heart failure is a condition characterized by high rate of hospital readmissions, increased rate of mortality and reduced quality of life. Data from the Nova Scotia (ICONS) registry was used to compare rehospitalisation and mortality among heart failure patients managed under heart failure clinic group and those managed under non clinic group. This comparative study brought out that management of HF patients in Heart failure clinics were associated with significant reduction in one year rehospitalisation and mortality (35\% versus $58 \%$, $P<0.001) .{ }^{4}$ Data analysis of the Trivandrum heart failure registry showed $12.5 \%$ and $18.1 \%$ of mortality rates after 30 and 90 days of follow up. ${ }^{5}$ An estimated increase in the prevalence of heart failure and its risk factors in the country represent an enormous burden on our health care system. ${ }^{6,7}$ As the prevalence, rehospitalisation and mortality associated with heart failure is rising at an alarming rate, it is conceivable to practice multidisciplinary patient focused approaches like heart failure clinics. Heart failure clinics are a powerful intervention made for the treatment of heart failure patients. HF clinics are patient centered clinics that have proved to reduce heart failure associated rehospitalisation and mortality. ${ }^{4}$ Multiple randomized and non-randomized clinical studies have proved that treatment in specialized heart failure clinics proved to significantly reduce the mortality rate and also to improve the quality of life of heart failure patients. ${ }^{8}$ Provision of education and interventions through heart failure clinics had projected to improve the outcomes of heart failure patients. ${ }^{9}$ Multidisciplinary care provided to congestive heart failure patients has shown to improve the patient's quality of life and reduce heart failure associated hospital readmissions. ${ }^{10}$

Majority of studies have evaluated the effectiveness of heart failure clinics in improving patient outcomes. But none of the studies from India had shown to compare heart failure clinics with the usual cardiac care given in outpatient department. Only limited number of health care providers in India practice the provision of patient focused care to heart failure patients through heart failure clinics. And also only a few hospitals in India have a dedicated well established heart failure clinic. This study was carried out in specialized cardiac care and Surgery hospital in Kerala. This study is the first of its kind to compare the occurrence of rehospitalisation and mortality in heart failure patients receiving personalized care in heart failure clinics and those receiving usual care in other cardiology outpatient department (OPD). The objective of the study was to assess patient health outcomes like mortality and rehospitalisation among heart failure patients receiving focussed care under HF clinics and those receiving usual care under regular cardiac outpatient department. 


\section{MATERIALS AND METHODS}

A retrospective comparative study was designed to compare the impact of heart failure clinics with general cardiac outpatient departments in reducing heart failure associated rehospitalisation and mortality. The study was carried out in a tertiary care Interventional Cardiology and Cardiac Surgery hospital with a dedicated well established heart failure clinic in Kochi, Kerala for a period of 1 year. Ethical clearance was granted by Institutional ethics committee of Lisie Hospital, Kochi. (Reg: ECR/40/inst/KL/2013/RR-16). The inclusion criteria to be satisfied for successful enrollment into the study included heart failure patients to be aged above 18 years, patients visiting heart failure clinic and other cardiology OPD for the first time in the year 2017 and those with NYHA stageI-IV of heart failure. Patients who failed to meet the inclusion criteria and those with incomplete medical data within the electronic medical record (EMR) were excluded from the study. All study relevant data were collected from the electronic medical record (EMR).

\section{Study procedure}

Institutional Review Board and Institutional Ethical Committee approval was obtained from the Hospital before the commencement of the study. The consort flowchart of the study design is depicted in Figure 1. A total of 200 heart failure patients who consulted in the heart failure clinic and other general cardiology OPD's of the hospital in the year of 2017 who satisfied the inclusion and exclusion criteria were selected for the study. Nearly 250 patients consulted for the first time in heart failure clinic in the year 2017 of which each even patient from the list was selected to be included in the study. And the second study group comprised of heart failure patients who consulted general cardiology OPDs on Friday's and Saturday's. Patients were followed retrospectively for a period of one year. Patient data were collected using a predesigned proforma. Patient data's regarding rehospitalisation and mortality were obtained at $1^{\text {st }}, 6^{\text {th }}$ and $12^{\text {th }}$ months from the electronic medical record (EMR). The data collected were then entered into the data collection form, was evaluated and different outcomes were then compared between the two groups.

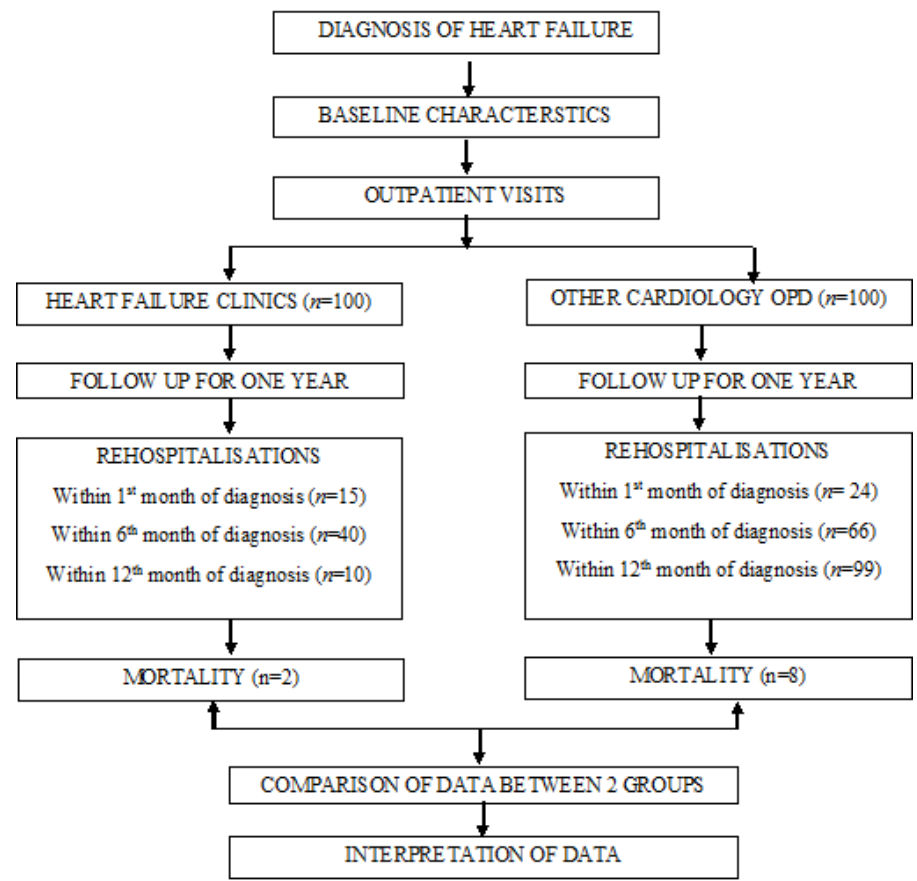

Figure 1: Consort flow chart of the study.
Patient outcomes like hospital readmission and mortality were compared between heart failure patients treated under heart failure clinics and patients treated in general cardiology outpatient departments.

\section{Statistical Analysis}

Data storage and analysis were performed using Microsoft Excel 2010 and SPSS Version 24. Independent sample $t$-test and paired $t$-test were used for the comparison of continuous variables. The Risk estimates and Odds ratio were calculated by Cross Tab method in SPSS. The Forest plots for odds ratio were plotted in excel. Cumulative survival curves were estimated by the Kaplan-Meir method and compared by the logrank test. All the $\mathrm{p}$ values were two-tailed and a significance level of $5 \%$ $(p<0.05)$ was used.

\section{RESULTS}

Demographic details such as age, gender, social habits, risk factors and comorbidities were collected from the patient records. All demographic parameters were then compared between the two study groups and as seen in Table 1, there exist no statistically significant differences. Hence the two study groups were comparable. We could see a male predominance in both the groups and majority of the patients in HF clinic were younger than those under general cardiology OPD. Mean age of the patients were $60.64 \pm 11.44$ in HF clinic and $63.62 \pm 10.48$ in other cardiology OPD. Among their social habits more smokers were reported in HF clinic whereas equal number of alcoholics in both study groups. The most prevalent risk factor was diabetes mellitus (60\% HF clinic vs $65 \%$ in other cardiology OPD) and the most reported comorbidity was anterior wall myocardial infarction (AWMI) among the 2 study groups. (42\%in both study groups). Both the study groups had majority of their patients diagnosed as having heart failure with reduced ejection fraction (96.66\% vs $80.48 \%)$

An analysis of the study outcomes projected that heart failure associated hospital readmissions within one year of diagnosis were significantly low among the heart failure clinic group. As evident from Figure 2,

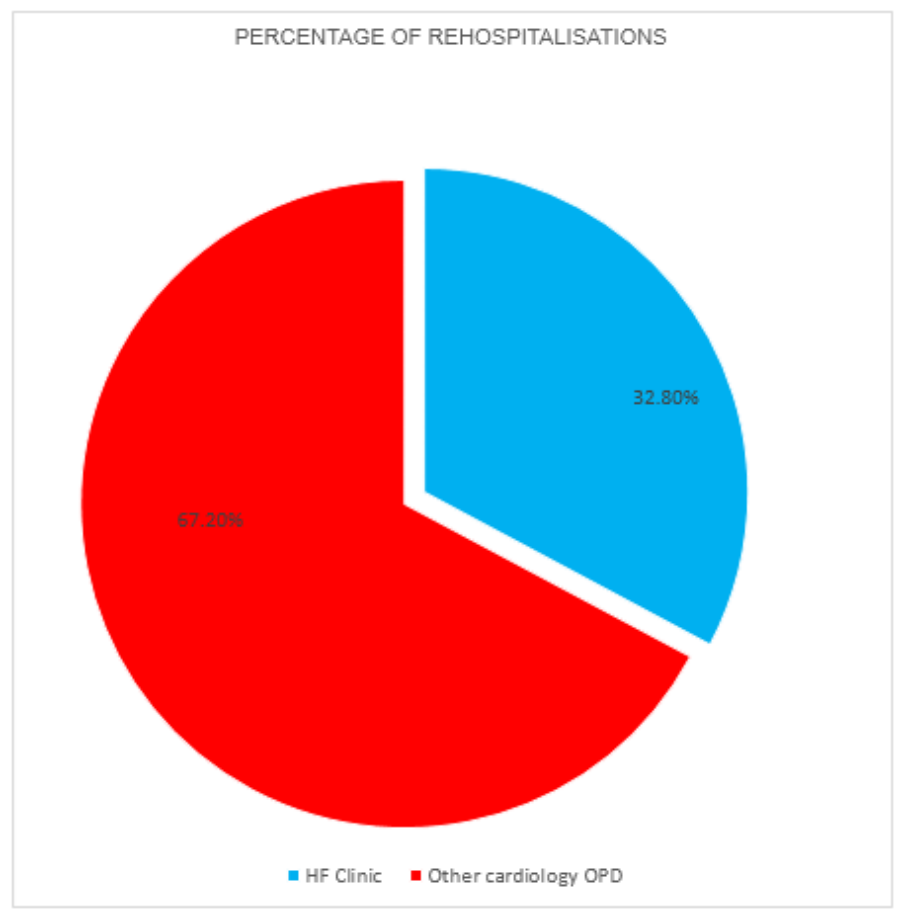

Figure 2: Total rehospitalisation HF clinic group vs other cardiology OPD. 
Table 1: Selected demographic parameters among the study groups.

\begin{tabular}{|c|c|c|c|c|}
\hline \multirow[t]{2}{*}{ Demographics } & \multicolumn{2}{|c|}{$\begin{array}{c}\% \text { of Patients in HF } \\
\text { Clinic }\end{array}$} & \multirow{2}{*}{$\begin{array}{c}\% \text { of patients in } \\
\text { other cardiology } \\
\text { OPD }\end{array}$} & \multirow[t]{2}{*}{$p$ value } \\
\hline & Male & $80 \%$ & & \\
\hline Gender & Female & $20 \%$ & $27 \%$ & 0.24 \\
\hline Smoking & & $56 \%$ & $53 \%$ & 0.67 \\
\hline \multirow[t]{3}{*}{ Alcoholic } & & $59 \%$ & $59 \%$ & 1.00 \\
\hline & $30-45$ & $9 \%$ & $8 \%$ & \multirow{6}{*}{0.24} \\
\hline & $46-60$ & $43 \%$ & $25 \%$ & \\
\hline \multirow[t]{4}{*}{ Age } & $61-75$ & $32 \%$ & $59 \%$ & \\
\hline & $76-90$ & $11 \%$ & $8 \%$ & \\
\hline & \multicolumn{3}{|c|}{ RISK FACTORS } & \\
\hline & & $\begin{array}{c}\text { No: OF } \\
\text { PATIENTS }\end{array}$ & No: OF PATIENTS & \\
\hline HTN & & $42(42 \%)$ & $41(41 \%)$ & 0.88 \\
\hline $\mathrm{DM}$ & & $60(60 \%)$ & $65(65 \%)$ & 0.46 \\
\hline DLP & & $27(27 \%)$ & $21(21 \%)$ & 0.32 \\
\hline Hypothyroidi & & $7(7 \%)$ & $6(6 \%)$ & 0.77 \\
\hline \multicolumn{2}{|c|}{ Hyperthyroidism } & $4(4 \%)$ & $2(2 \%)$ & 0.40 \\
\hline \multicolumn{5}{|c|}{ CO MORBIDITIES } \\
\hline CAD & & $35(35 \%)$ & $32(32 \%)$ & 0.65 \\
\hline ANGINA & & $7(7 \%)$ & $5(5 \%))$ & 0.55 \\
\hline AWMI & & $42(42 \%)$ & $42(42 \%)$ & 1.00 \\
\hline $\mathrm{AF}$ & & $8(8 \%)$ & $10(10 \%)$ & 0.62 \\
\hline CARDIOMYOP & ITHY & $19(19 \%)$ & $15(15 \%)$ & 0.45 \\
\hline STROKE & & $3(3 \%)$ & $2(2 \%)$ & 0.65 \\
\hline CLD & & $4(4 \%)$ & $1(\%)$ & 0.17 \\
\hline CKD & & $10(10 \%)$ & $16(16 \%)$ & 0.20 \\
\hline
\end{tabular}

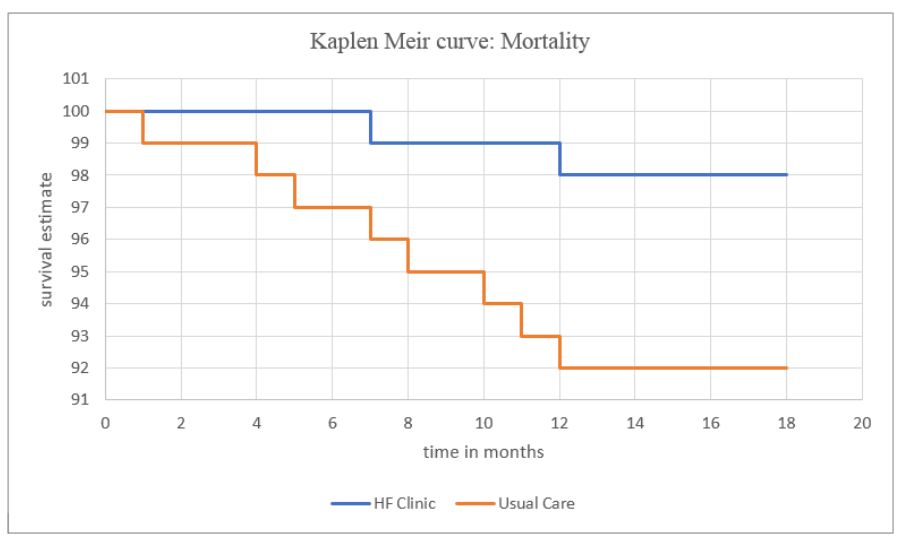

Figure 3: Kaplan meier survival curve of one year mortality among HF clinic(blue line) and usual care cardiology OPD (red line). Mortality rate was significantly low among the HF clinic group. only $32.8 \%$ of hospital readmissions were from HF clinic whilst $67.2 \%$ were reported from other cardiology OPD. Severe heart failure was the major contributing factor towards readmission in both study groups. Within one year of diagnosis, only 10 events of rehospitalisations were experienced by the heart failure clinics group, whereas 99 events of rehospitalisation were reported among the usual care patients. Table 2 shows the statistically significant difference observed for rehospitalization when compared between patients in HF clinic and other cardiology OPD within $6^{\text {th }}$ and $12^{\text {th }}$ month $(p<0.05)$. Severe heart failure was the major cause for readmission among the usual care cardiology OPD patients. A comparatively lower number of rehospitalisations due to severe HF were reported in HF clinic. Reduced number of readmissions in heart failure clinics were attributed to the provision of multidisciplinary patient focused care which included timely follow up, drug dose titration, medication adherence management and education of heart failure patients.

The adjusted one year outcomes of heart failure clinics and usual care cardiology OPD patients are listed in Table 3. The relative risk for rehospitalisation was found to be 0.556 (at lower interval of 0.384 and upper interval of 0.805 ). The relative risk reduction or RRR was estimated to be 0.444 . This confirms that the patients in heart failure clinics have a $44.4 \%$ lower chances of being rehospitalised with heart failure.

Rehospitalisation due to causes other than heart failure were also reported among the 2 study groups, (Table 4 ) of which a greater fraction was among the usual care patients $(p=0.00)$. Coronary artery disease or CAD (8 vs 22) and chronic kidney disease (CKD) (7 vs 12) were the most common cause for readmission in both groups (HF vs other cardiology OPD).

The total events of death reported within one year of diagnosis of heart failure are included in Table 5. A total of 10 events of deaths were reported and of these only 2 patients (20\%) were under HF clinic group, all other reported deaths were among the usual care cardiology OPD patients. Chi square test was applied and statistically significant difference was obtained when mortality rate was compared between the 2 study groups. Figure 3 depicts the Kaplan-Meier survival function estimate of oneyear total mortality in heart failure clinic care (Blue line) versus other cardiology OPD (redline) groups. Adjusted survival was significantly better for those who underwent care in a heart failure clinic than for those followed by other cardiology OPD. Relative risk for mortality was estimated to be 0.338 (at lower interval of 0.111 and higher interval of

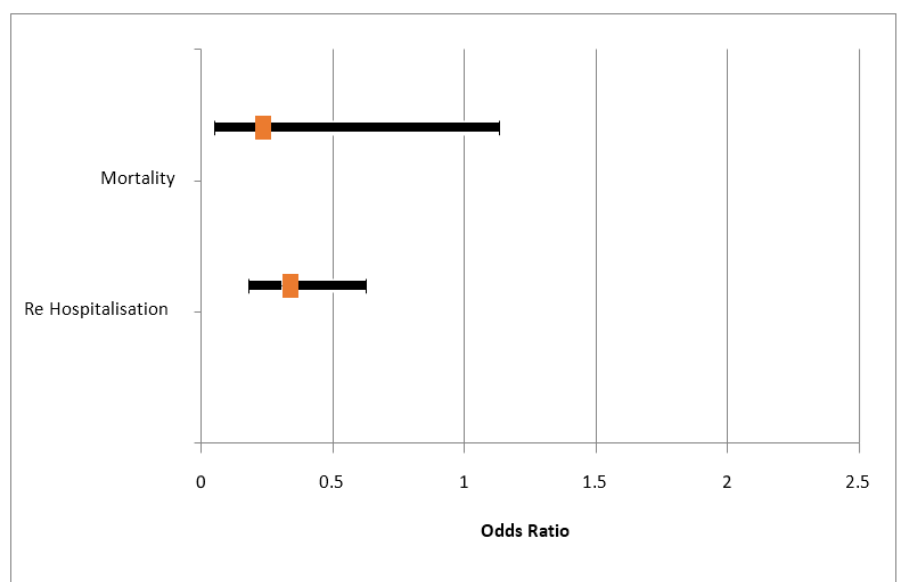

Figure 4: Forest plot for one year rehospitalization and mortality. Odds ratio less than 0.5 means that the HF clinic group are at low risk of rehospitalization and mortality when compared to usual care cardiology OPD. 
Table 2: Number of events of rehospitalisation reported within $1^{\text {st }}, 6^{\text {th }}$ and $12^{\text {th }}$ month in HF clinic and other cardiology OPD.

\begin{tabular}{cccc}
\hline & Category & $\begin{array}{c}\text { Mean No: of } \\
\text { events }\end{array}$ & $\begin{array}{c}p \\
\text { value }\end{array}$ \\
\hline $\begin{array}{c}\text { Number of times } \\
\text { rehospitalised within } 1^{\text {st }} \\
\text { Month }\end{array}$ & HF Clinic & 15 & \\
$\begin{array}{c}\text { Other } \\
\text { Number of times }\end{array}$ & 24 & 0.12 \\
$\begin{array}{c}\text { cardiology OPD } \\
\text { rehpitalised within } 6^{\text {th }} \\
\text { month }\end{array}$ & HF Clinic & 40 & \\
$\begin{array}{c}\text { Number of times } \\
\text { rehospitalised within 12 }\end{array}$ & Other & 66 & 0.01 \\
month & HF Clinic & 10 & \\
& Other & 99 & 0.00 \\
\hline
\end{tabular}

Table 3: One year outcomes of heart failure clinics vs usual care cardiology OPD patients.

\begin{tabular}{ccccc}
\hline 1-year outcome & Hazard ratio & 95\% Cl & NNT & $P$ value \\
\hline Mortality & 0.235 & $0.049-1.134$ & 17 & 0.05 \\
Rehospitalisation & 0.338 & $0.183-0.627$ & 5 & 0.00 \\
\hline
\end{tabular}

1.350) and the relative risk reduction or RRR was 0.612 . This means that there was a $61.2 \%$ reduction in risk that a patient treated under heart failure clinic may die from heart failure when compared to those receiving usual care in cardiac OPD.

Forest plots for one year outcomes are shown in Figure 4 and it is clear that the Odds Ratio for both rehospitalisation and mortality are less than 1. This highlights that the chances of mortality and rehospitalisation is less in the HF clinic when compared to usual care cardiology OPD. The NNT to avoid one episode of rehospitalisation in HF clinic was calculated to be 5 and the corresponding NNT for mortality was 17 .

\section{DISCUSSION}

Heart failure is one of the primary cause of hospital admissions in many high income countries and globally it contributes to $1-2 \%$ of hospital admissions. ${ }^{11}$ Despite the advancements in pharmacological and nonpharmacological management of heart failure, mortality rate still remains high. ${ }^{12}$ Epidemiological studies conducted outside India clearly states that heart failure is a staggering health issue with high economic burden, hospitalization and mortality rates. ${ }^{13}$ In a country like India management of heart failure patients in an established heart failure clinic can be considered as a promising approach that can contribute towards reduced hospital expenditures, lower incidences of heart failure associated hospital admissions and reduced mortality. Our study clearly highlighted that treatment of heart failure patients in a multidisciplinary patient focused heart failure clinic is associated with significant reduction in heart failure readmissions and mortality.

The Trivandrum heart failure registry that enrolled 1205 heart failure patients suggested that majority of these heart failure patients were men. Also a 90 day outcome study based on this registry observed that heart failure was associated with an increased number of hospital readmissions and mortality. ${ }^{4}$ Our study also demonstrated a male predominance among heart failure patients. Our data analysis clearly stated that the practice of heart failure clinic significantly reduced heart failure associated hospital readmissions and mortality.
Table 4: Rehospitalisation due to other causes excluding HF.

\begin{tabular}{|c|c|c|c|c|}
\hline & & HF Clinic & $\begin{array}{c}\text { Other cardiology } \\
\text { OPD }\end{array}$ & $\begin{array}{c}P \\
\text { value }\end{array}$ \\
\hline \multirow{2}{*}{$\begin{array}{l}\text { Rehospitalisation due } \\
\text { to other causes }\end{array}$} & $\begin{array}{c}\text { No: of } \\
\text { patients }\end{array}$ & $\begin{array}{c}13 \\
(28.88 \%)\end{array}$ & $32(71.12 \%)$ & \\
\hline & $\begin{array}{l}\text { No: of } \\
\text { events }\end{array}$ & $\begin{array}{c}14 \\
(18.91 \%)\end{array}$ & $60(81.09 \%)$ & 0.000 \\
\hline
\end{tabular}

Table 5: Number of deaths reported among both study groups.

\begin{tabular}{lccccc} 
& & HF Clinic & $\begin{array}{c}\text { Other } \\
\text { cardiology } \\
\text { OPD }\end{array}$ & $\begin{array}{c}\text { Chi square } \\
\text { value }\end{array}$ & $\begin{array}{c}p \\
\text { value }\end{array}$ \\
\hline Mortality & No: of deaths & 2 & 8 & 3.78 & 0.05 \\
\hline
\end{tabular}

The INDUS study conducted at AIIMS by Chaturvedi et al. Which was the first of its kind from India to estimate the prevalence of community based heart failure observed that there was a $1 \%$ prevalence of heart failure in India with an estimated mortality rate of 0.1-0.16 million patients each year. ${ }^{6}$ Howlett et al. done a retrospective comparative study on heart failure patients treated in heart failure clinics and non-clinics. This study which was based on the Nova Scotia ICONS registry clearly concluded that the real world management of heart failure patients in heart failure clinics clearly had a significant impact in reducing heart failure associated rehospitalisation and mortality. ${ }^{7}$ A research based on the Swede HF registry by Savarese et al. evaluated the impact of nurse led heart failure clinics in reducing rehospitalisation and mortality reported that these nurse led heart failure clinics significantly reduced the mortality rates associated ${ }^{10}$ failure clinics significantly reduced heart failure associated rehospitalisations and mortality rate. Several meta-analysis based on multiple clinical studies have reported a $20-30 \%$ reduction in mortality rates and a $25-70 \%$ reduction in heart failure associated readmissions. ${ }^{14-16}$ Our data analysis also had the same pattern that heart failure clinics were associated with reduced hospital readmissions. Of the total number of heart failure associated readmissions in a year, only 65 events were reported in heart failure clinics whereas 189 incidences of heart failure rehospitalisations were reported under general OPDs. The number of one year rehospitalisations was significantly lower in patients treated in heart failure clinics when compared to those in other cardiology OPD (65 vs 185$)(p \leq 0.05)$. Hospital readmissions due to causes other than heart failure were also assessed among the patients of either study groups and it was seen that heart failure clinic group had a lower incidence of readmissions. Chronic kidney disease and coronary artery disease were the main causes that contributed towards these readmissions. Mortality rates were also low in heart failure clinics. Ten events of heart failure associated deaths were reported within a year, of which $80 \%$ were from other cardiology OPDs. Only $20 \%$ of deaths were from heart failure clinics. All these evidences were conclusive towards the fact that provision of focused patient care through heart failure clinics were associated with reduced hospital readmissions and mortality.

\section{CONCLUSION}

Management of heart failure patients in heart failure clinic was associated with significant reduction in one year mortality and rehospitalisation. Patients treated under heart failure clinics received personalized patient focused care which contributed to this reduced hospital readmissions and mortality rates. New strategies should be adopted to widely establish the concept of heart failure clinics. Future research should focus on the 
impact of establishing such specialized clinics for the management of chronic diseases.

\section{ACKNOWLEDGEMENT}

We are profoundly grateful to Dr. Suja Abraham, Associate Professor, Department of Pharmacy practice, for her excellent guidance innovative ideas and immense help rendered at various stages of the study. We express our gratitude to Dr. Jabir Abdulla kutty, Cardiologist, Lisie Hospital, Kochi for his guidance and support at various stages of the study. We also thank the Research department, and ethics committee, Lisie Hospital, Kochi, for approving our study protocol and for providing the site of study.

\section{CONFLICT OF INTEREST}

The authors declare no conflict of interest.

\section{ABBREVIATIONS}

HF: Heart failure; OPD: Outpatient department; EMR: Electronic medical record; NYHA: New York Heart Association; CAD: Coronary artery disease; CKD: Chronic kidney disease.

\section{REFERENCES}

1. Ponikowski P, Voors AA, Anker SD, Bueno H, Cleland JG, Coats AJ, et al.: ESC Guidelines for the diagnosis and treatment of acute and chronic heart failure. Eur Heart J. 2016;37(27):2129-200

2. Mosterd A, Hoes AW. Clinical epidemiology of heart failure. Heart. 2007;93(9):1137-46

3. Redfield MM, Jacobsen SJ, Burnett JC, Mahoney DW, Bailey KR, Rodeheffer RJ. Burden of systolic and diastolic ventricular dysfunction in the community: appreciating the scope of the heart failure epidemic. JAMA. 2003;289(2):194202.
4. Howlett JG, Mann OE, Baillie R, Hatheway R, Svendsen A, Benoit R, et al. Heart failure clinics are associated with clinical benefit in both tertiary and community care settings: Data from the Improving Cardiovascular Outcomes in Nova Scotia (ICONS) registry. Can J Cardiol. 2009;25(9):306-11.

5. Harikrishnan S, Sanjay G, Anees T, Viswanathan S, Vijayaraghavan G, Bahuleyan CG, et al. Clinical presentation, management, in-hospital and 90-day outcomes of heart failure patients in Trivandrum, Kerala, India: The Trivandrum Heart Failure Registry. Eur J Heart Fail. 2015;17(8):794-800.

6. Huffman MD, Prabhakaran D. Heart failure: Epidemiology and prevention in India. The National Medical Journal of India. 2010;23(5):283-8.

7. Chaturvedi V, Parakh N, Seth S, Bhargava B, Ramakrishnan S, Roy A, et al. Heart failure in India: The INDUS (INDiaUkieri Study) study. J Pract Cardiovac Sci. 2016;2(1):28-35.

8. Gustafsson F, Arnold JM. Heart failure clinics and outpatient management: review of the evidence and call for quality assurance. Eur Heart J. 2004;25(18):1596-604.

9. Krumholz HM, Amatruda J, Smith GL, Mattera JA, Roumanis SA, Radford MJ, et al. Randomized Trial of an Education and Support Intervention to Prevent Readmission of Patients With Heart Failure. J Am Coll Cardiol. 2002;39(1):83-9.

10. Savarese G, Lund LH, Dahlstorm U Stomberg A. Nurse led heart failure clinics are associated with reduced mortality but not heart failure hospitalization. J Am Heart Assoc. 2019;8(10):1-12.

11. Ambrosy AP, Fonarow GC, Butler J, Chioncel O, Greene SJ, Vaduganathan M, et al. The global health and economic burden of hospitalizations for heart Failure Lessons learned from hospitalized heart failure registries. J Am Coll Cardiol. 2014;63(12):1123-33.

12. Bytyçi I, Bajraktari G. Mortality in heart failure patients. Anatol J Cardiol. 2015;15:63-8.

13. Roger VL. Epidemiology of Heart Failure. Circ Res. 2013:113(6):646-59

14. Gustafsson F, Arnold JM. Heart failure clinics and outpatient management: Review of the evidence and call for quality assurance. Eur Heart $\mathrm{J}$. 2004;25(18):1596-604.

15. Heidenreich PA, Ruggerio CM, Massie BM. Effect of a home monitoring system on hospitalization and resource use for patients with heart failure. Am Heart J. 1999;138(4):633-40

16. Stewart S, Horowitz JD. Home-based intervention in congestive heart failure: Long-term implications on readmission and survival. Circulation. 2002;105(24):2861-6.

Article History: Submission Date : 27-04-2020; Revised Date : 21-06-2020; Acceptance Date : 22-07-2020

Cite this article: James J, Stephy PS, Joseph J, Abraham S, Abdullakutty J. Impact of Focussed Care in Heart Failure Patients on Hospital Readmission and Mortality. J Young Pharm. 2020;12(3):261-5. 